TAPROBANICA, ISSN 1800-427X. November, 2020. Vol. 09, No. 02: pp. 205-209, pl. 55-57.

(C) Research Center for Climate Change and Department of Biology, Faculty of Mathematics \& Natural Sciences, University of Indonesia, Depok 16424, INDONESIA.

http://www.taprobanica.org/

https://doi.org/10.47605/tapro.v9i2.232

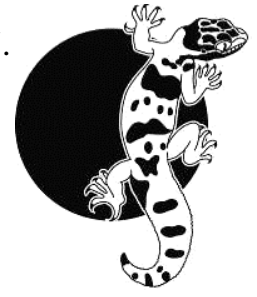

\title{
REDESCRIPTION OF Minervarya nicobariensis (STOLIZKA, 1870) (AMPHIBIA: DICROGLOSSIDAE) WITH A NEOTYPE DESIGNATION
}

\author{
S.R. Chandramouli ${ }^{1,2} \&$ K.V. Devi Prasad ${ }^{1}$ \\ ${ }^{1}$ Department of Ecology and Environmental Sciences, School of Life Sciences, Pondicherry University, \\ Puducherry 605014, India \\ ${ }^{2}$ Corresponding author. E-mail: findthesnakeman@gmail.com
}

\begin{abstract}
The poorly-known, insular endemic frog species, Minervarya nicobariensis (Stoliczka, 1870) is redescribed based on new material from the Nicobar Archipelago. A neotype is designated as its holotype had been lost. Novel data on biology, ecology, distribution and natural history of this poorly known species are provided. Breeding biology and larval morphology are described in detail. Potential threats to the species are discussed and an assessment of its conservation status is attempted.
\end{abstract}

Key words: Distribution, endemic, India, larval morphology, natural history, Nicobar Archipelago

\section{Introduction}

Sanchez et al. (2018) revised the widespread dicroglossid frog genus Fejervarya Bolkay, 1915. This revision resulted in the transfer of several South and Southeast Asian members of the genus to Minervarya Dubois, Ohler \& Biju 2001 either expressly or by implication, including the new combination Minervarya nicobariensis", that was originally described as "Rana gracilis var. nicobariensis" from "the Nicobars, in the neighbourhood of Nancowry Harbor" based on a single juvenile specimen. This type specimen was reported to have been lost (Dubois 1984, Chanda et al. 2001). It was then attributed as a subspecies of $R$. limnocharis by Sclater (1892). Not having been able to examine the type of $R$. $g$. var. nicobariensis, Dubois (1984) speculated on the possibility that the species nicobariensis was a synonym of
Fejervarya andamanensis. Therefore, Dubois (1987) regarded that nomen, nicobariensis to be incertae sedis. Subsequently, Dubois \& Ohler (2000) included this taxon in the genus Fejervarya as a species that was "still unsufficiently characterized in published works" (sic) which would also have to be considered in any global revision of the genus. Against this backdrop, we present this paper in order to stabilise the taxonomic status of $M$. nicobariensis, specifically, because new material is available from the Nicobars which we designate a neotype and report additional observations of this species.

\section{Material and methods}

The islands of the Nicobar Archipelago were surveyed in July 2017 to record the target species. Specimens were measured using digital 
callipers to the nearest $0.1 \mathrm{~mm}$. One adult female and two adult males found dead on roads were also collected from Camorta and Great Nicobar respectively. The following morphometric characters were recorded: snoutvent length (SVL, from the tip of the snout to the anterior margin of the cloaca), axilla-groin distance (AG, from the posterior margin of the forelimb at its insertion point on the body to the anterior margin of the hind limb at its insertion point on the body), head length (HL, from the posterior edge of the mandible to the tip of the snout), head width (HW, the maximum width of the head at the angle of the jaws), head depth (HD, the maximum depth of the head), body width (BW, the maximum width of the body at the trunk), eye diameter (ED, the greatest horizontal diameter of the orbit), eye-nostril distance (EN, from the anterior border of the orbit to the middle of the nostril), eye-snout distance (ES, from the anterior border of the orbit to the tip of the snout), eye-tympanum length (ETY, from the posterior border of the orbit to the anterior border of the tympanum), upper eyelid width (UEW, the maximum width of the upper eyelid), interorbital distance (IO, distance between the upper eyelids), internarial distance (IN, distance between the nostrils), tympanum diameter (TYD, the greatest horizontal diameter of the tympanum), upper arm length (UAL, from the axilla to elbow), lower arm length (LAL, from the posterior margin of the elbow to the base of the outer metacarpal tubercle), palm length (PAL, from the posterior border of the outer metacarpal tubercle to tip of the $3^{\text {rd }}$ finger), femur length (FEL, from the cloaca to the knee), tibia length (TBL, from knee to heel), foot length (FOL, from inner metatarsal tubercle to the tip of the $4^{\text {th }}$ toe). Webbing formulae follows Savage \& Heyer (1997).

The following measurements of tadpoles were recorded: TotL, total length; TaL, tail length; HBL, head-body length; HBW, headbody width; HBD, head-body depth; ED, eye diameter; EN, eye-nostril length; ES, eye snout length; ODW, oral disc width; IO, inter-orbital distance; IN, internarial distance; $\mathrm{CFH}$, caudal fin height; and $\mathrm{CMH}$, caudal muscle height, following Chandramouli \& Kalaimani (2014). Geographic coordinates of the localities of records of this species were mapped using a GPS (WGS84 datum). Colour descriptions made here are based on photographs taken of live specimens. Calls were recorded in the natural habitat using a digital audio recorder and analyzed using the software packages Adobe Soundbooth CS3 and Adobe Audition 1.0. One specimen of $M$. nicobariensis was radiographed to examine osteological features and its osteology is described. Osteological terminology follows Noble (1931).

\section{Systematics}

While describing Rana gracilis var. nicobariensis, Stoliczka (1870) defined this taxon based on the following suite of morphological characters: "short snout", "very slight webbing of the feet", "hardly extends to half the length of the toes", "the toes being considerably elongated and slender, the fourth equals in length to very nearly half the body". Specimens with the above characteristics, matching the description of $R$. $g$. var. nicobariensis were encountered in Camorta, Nancowry, Katchall and Great Nicobar Islands. An adult female specimen found (ZSI/ANRC/T/12326) from the vicinity of the original type locality showed all of the diagnostic characters listed above. As the original description was brief and the holotype is lost or destroyed, in order to stabilize its taxonomic status we designate and redescribe the above specimen as the neotype below.

\section{Minervarya nicobariensis (Stoliczka, 1870)}

(Figs. 1-8; Table 1)

Rana gracilis var. nicobariensis Stoliczka, 1870

Rana limnocharis var. nicobariensis - Sclater (1892)

Fejervarya nicobariensis - Dubois \& Ohler (2000)

Minervarya nicobariensis — Sanchez et al. (2018)

Neotype (designated herein). An adult female, ZSI/ANRC/T/12326, SVL $63.88 \mathrm{~mm}$, collected from Munak, Camorta Island [in the vicinity of the holotype locality fide Stoliczka 1870], the central group of Nicobar Archipelago, India, by S.R. Chandramouli on 25 June 2017.

Other material examined $(\boldsymbol{n}=2)$. Adult males, DOSMB 05012, DOSMB 05015 (SVL $34.88,38.35 \mathrm{~mm}$ respectively), collected from Campbell Bay, Great Nicobar Island, India, by S.R. Chandramouli on 22 July 2017.

Tadpoles $(n=3$; stage 25). DOSMB 05023a-c, collected from a dried up, roadside puddle near Govind Nagar, Great Nicobar Island, India; collector same as the above, and date unknown. 


\section{Plate 55}
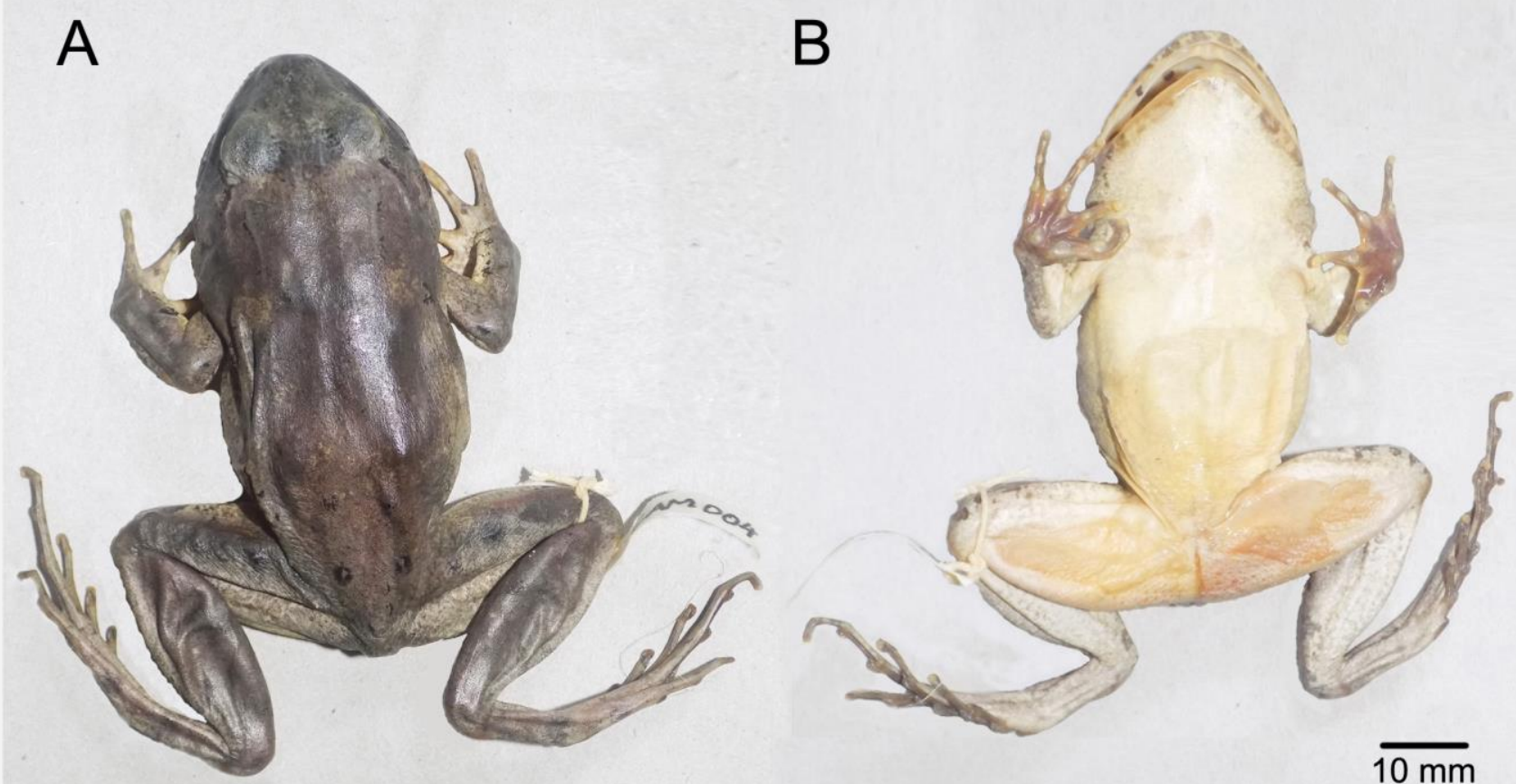

Figure 1. (A) Dorsal and (B) ventral view of the neotype of Minervarya nicobariensis (an adult female, ZSI /ANRC/T/12326) from Camorta Island, Nicobar

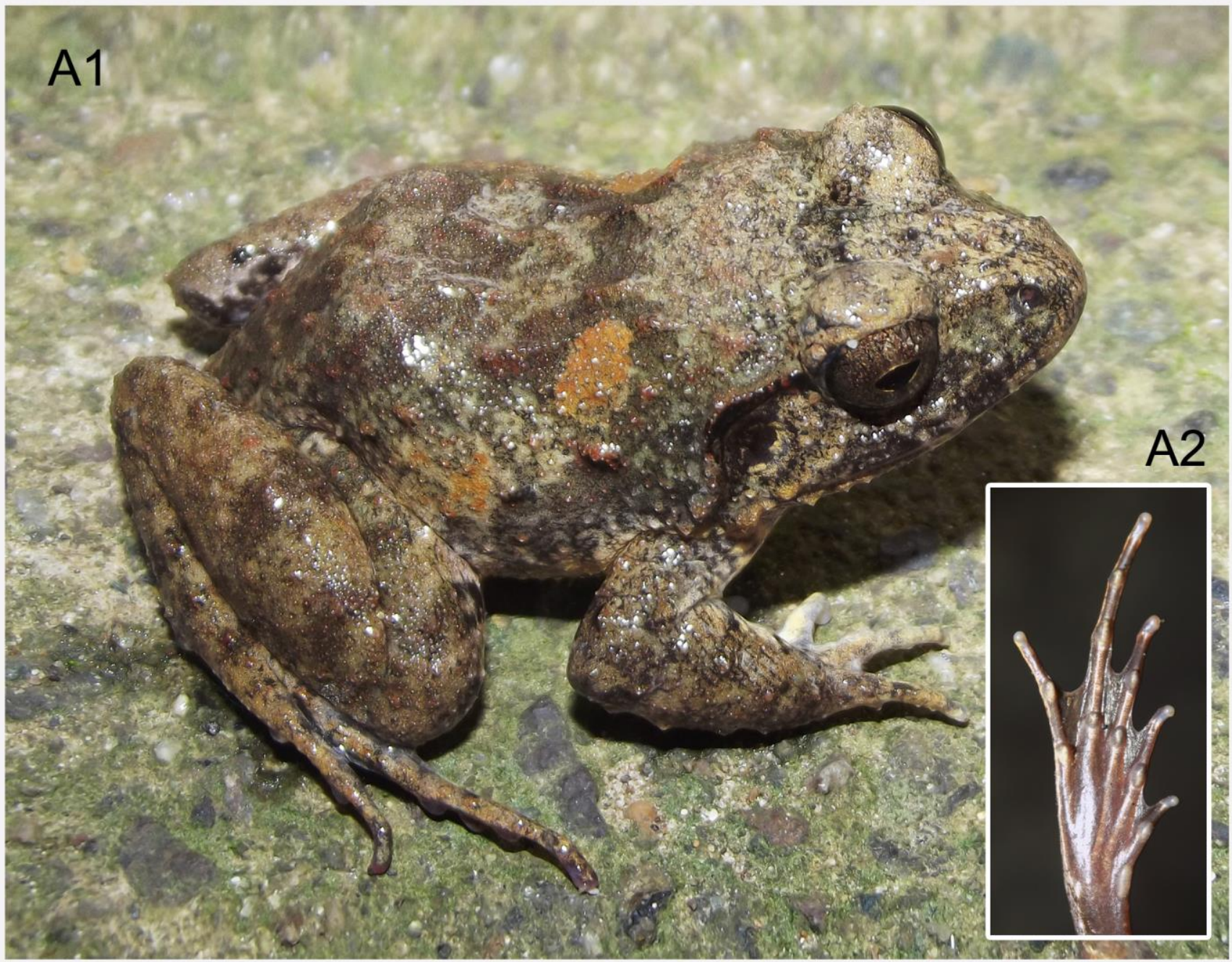

Figure 2. M. nicobariensis from Camorta Island, Nicobar (A1) an adult male (not collected) (A2) toe webbing 


\section{Plate 56}
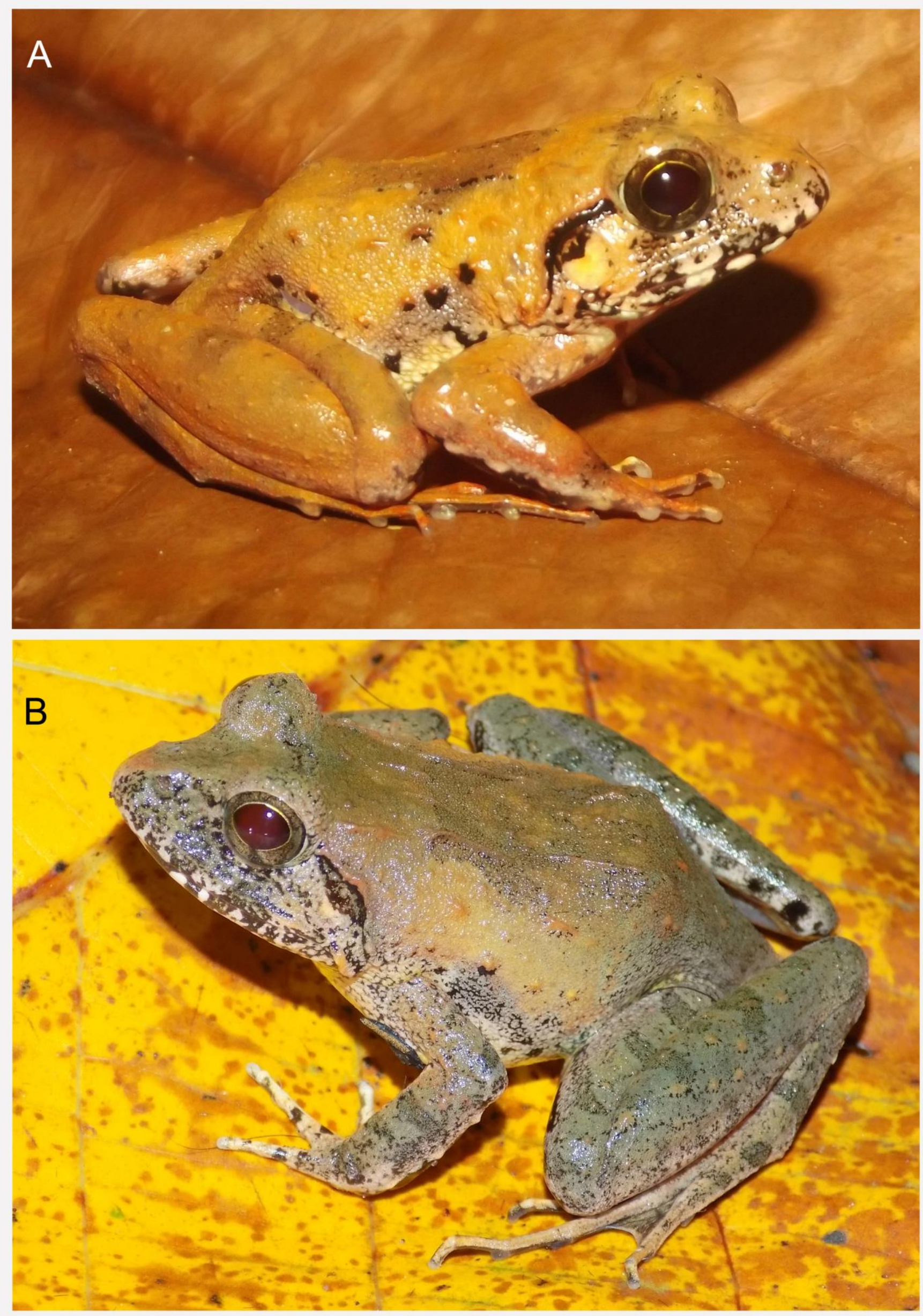

Figure 3. An adult Minervarya nicobariensis from Great Nicobar Island (not collected) (A) male and (B) female 


\section{Revised Diagnosis}

Minervarya nicobariensis, an endemic to islands of the central and southern group of the Nicobar Archipelago, is diagnosed by the moderate to large adult body size (34.88-63.88 $\mathrm{mm}$ SVL), a relatively short and blunt snout tip, absence of rictal glands near lips, presence of short and interrupted skin folds on the dorsum, presence of a pair of fejervaryan lines along the sides of the belly, moderately developed toe webbing, not exceeding the penultimate subarticular tubercle of toe IV, presence of a single median gular vocal sac in males, and finger and toe tips with blunt and rounded terminus.

Description of the neotype. An adult female, SVL $63.88 \mathrm{~mm}$. Head short (HL:SVL 0.38) and broader than long (HL:HW 0.88) with a blunt, rounded snout tip; nostrils located between the snout tip and the eyes (EN:ES 0.49); eyes relatively large (ED:HL 0.34) with a rhomboidal pupil; upper eyelids slightly broader than interorbital distance (0.92); internarial space wider than inter orbital space (IO:IN 0.95); tympanum relatively large and conspicuous, smaller than the eyes (TYH:ED 0.61); an evident, thick supratympanic fold commencing from post orbital region to the jaw angle; upper arms short (UAL:SVL 0.23); lower arms about as long as the upper arms (UAL:LAL 1.01); palm longer than lower arm; inner metacarpal tubercle smaller than the outer metacarpal tubercle of the palm; thigh about half as long as the body (FEL:SVL 0.53); shank as long as the thighs (FEL:TBL 1.00); foot a little shorter than the thigh; toes partially webbed; webbing formula I 0.5-1, II 0.5-1.5, III 0.5-2, IV 2.5-1, V; inner metatarsal tubercle vertically elongate and prominent; outer metatarsal tubercle absent.

Colouration. Overall colouration of the dorsum greyish brown; with a feeble black coloured ' $\mathrm{H}$ ' mark in the middle, flanked by two bright orange spots; forearms and hind-limbs with black bars; posterior surface of the thighs pink coloured; groin yellowish; upper lips with two dark subocular spots; gular region white and unpatterned; venter uniform white.

Variation. Males (mean SVL $36.62 \mathrm{~mm}$ ) are smaller than the female neotype and have a single median gular vocal sac with small black spots and a thick white nuptial pad on the dorsal surface of the first finger (both absent in females); dorsal colouration variable from brown, with two orange spots and a dark brown ' $\mathrm{H}$ ' shaped marking at mid-body to golden orange with feeble brown dorsal markings; intensity of dark bands on the hind-limbs variable from feeble to dark. Measurements are presented in Table 1.

Table 1. Measurements of the neotype, a female (f), and two male (m) specimens of Minervarya nicobariensis

\begin{tabular}{lccc}
\hline Character & $\begin{array}{c}\text { ZSI/ } \\
\text { ANRC/T/ } \\
12326\end{array}$ & $\begin{array}{c}\text { DOSMB } \\
05012\end{array}$ & $\begin{array}{c}\text { DOSMB } \\
05015\end{array}$ \\
\hline Sex & $\mathrm{f}$ & $\mathrm{m}$ & $\mathrm{m}$ \\
SVL (mm) & 63.88 & 34.88 & 38.35 \\
Axilla-Groin length & 27.04 & 11.53 & 10.62 \\
Head length & 23.96 & 13.95 & 14.26 \\
Head width & 27.11 & 13.33 & 14.24 \\
Head depth & 11.88 & 6.11 & 8.51 \\
Eye diameter & 8.26 & 4.71 & 4.62 \\
Eye-nostril length & 5.52 & 2.9 & 3.24 \\
Eye-snout length & 11.16 & 5.09 & 5.08 \\
Tympanum diameter & 5.0 & 2.07 & 2.02 \\
Eye-tympanum & 3.25 & 1.36 & 1.03 \\
Upper eyelid width & 5.5 & 2.91 & 2.31 \\
Inter-orbital distance & 5.04 & 1.9 & 2.06 \\
Internarial distance & 5.31 & 2.78 & 2.21 \\
Upper arm length & 14.48 & 6.87 & 8.05 \\
Lower arm length & 14.4 & 7.77 & 8.5 \\
Palm length & 15.87 & 8.59 & 9.24 \\
Femur length & 33.87 & 18.05 & 20.06 \\
Tibia length & 33.82 & 21.45 & 22.51 \\
Tarsus length & 16.19 & 10.07 & 10.26 \\
Foot length & 32.31 & 18.63 & 21.15 \\
\hline
\end{tabular}

Larval description. Stage 25 larvae of Minervarya nicobariensis are described herein (Fig. 4). The larvae measure $15.0-16.0 \mathrm{~mm}$ in total length (15.67 $\mathrm{mm} \pm 0.58)$; body streamlined, head-body relatively short (HBL:TotL 0.31); longer than broad (HBL:HBW 1.45) and broader than deep (HBD:HBW 0.64); tail much longer, more than twice as long as head-body (HBL:TaL 0.45); eyes small (ED:HBL 0.24), dorsolateral in position, separated from each other by a wider space than between the nares (IO:IN 1.29); oral disc oriented antero-ventrally, small (ODW 0.76 $\mathrm{mm}$ ), keratinized beak with a long, downward curved lateral process and three rows of keratodont, labial tooth row formula: $2 / / 1+1 / 1$; marginal papillae large and well developed; spiracle sinistral; vent tube dextral.

Larval colouration. Overall dorsal colouration sandy brown with intermittent small and large black spots scattered throughout the body; caudal muscles orange in colour with black spots laterally; venter uniform and translucent through which, the highly coiled gut is visible. 


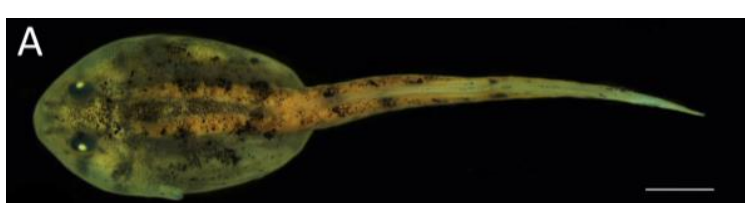

B
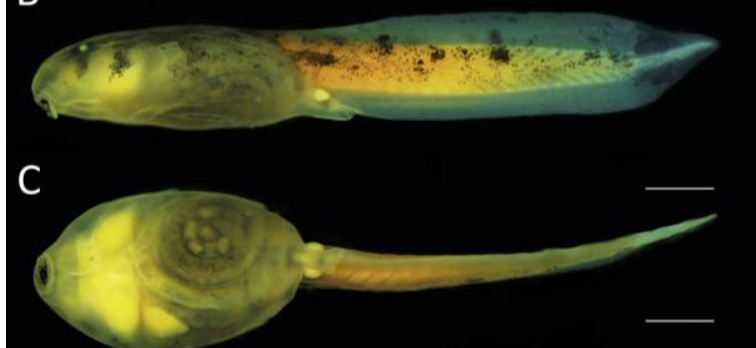

D

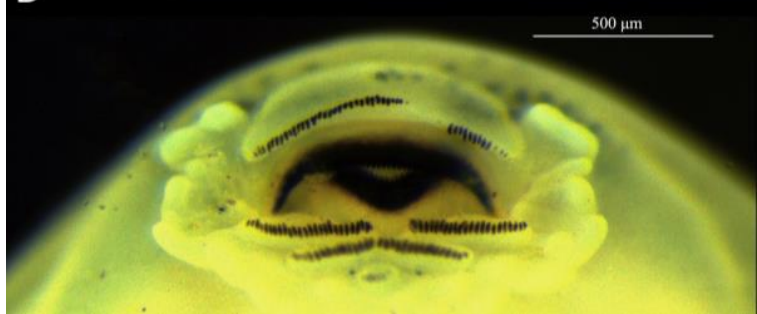

Figure 4. The tadpole (stage 25) of Minervarya nicobariensis from Great Nicobar (A) dorsal, (B) lateral, (C) ventral view of the body, and (D) mouthparts; Scale: $2 \mathrm{~mm}$

Call description. Call of Minervarya nicobariensis described herein (Fig. 5) is based on a recording of an adult male (SVL $\sim 40 \mathrm{~mm}$ ) from Katchall Island in the central group of the Nicobar Archipelago.

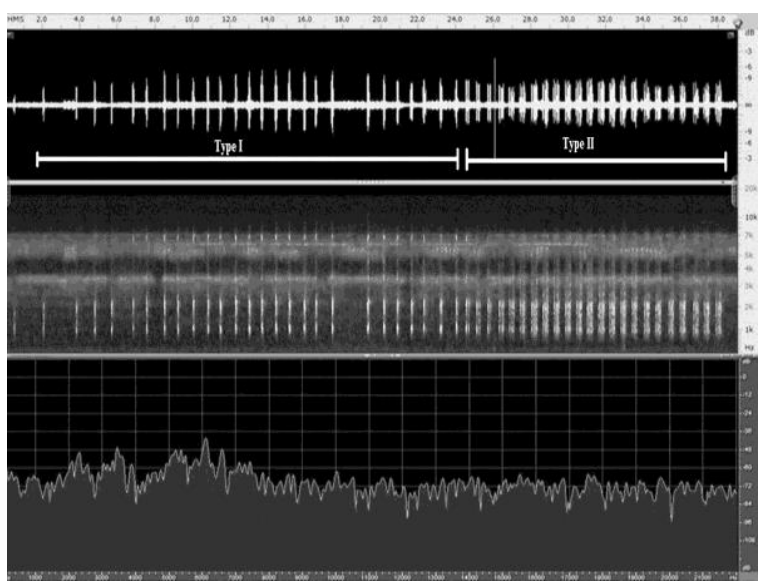

Figure 5. Call characteristics of $M$. nicobariensis (oscillogram, spectrogram, and power spectrum respectively), recorded from Katchall Island, Nicobar

The call is composed of a multi-pulsed note comprising pulses of two types, among which the first 26 pulses are monosyllables of 'croak', followed by 23 pulses of type II, which are composed of a series of repeated syllables of 'cro-cro-cro-croak'. Each syllable of type I lasts for a mean duration of $0.15 \mathrm{~s} \pm 0.02$, while those of type II last for $0.27 \mathrm{~s} \pm 0.02$. Dominant frequency of the call was at $6 \mathrm{kHz}$, with mean amplitude of $-6 \mathrm{~dB}$ for type I and $-9 \mathrm{~dB}$ for type II calls.

Osteology. Fig. 6. Skull large with an obtusely pointed snout tip; frontoparietals relatively slender and elongate; nasals triangular, broader than long; orbital cavities large, as long as the frontoparietals; pectoral girdle firmisternal with slender coracoids and clavicles; humerus as long as the radioulna; phalangeal formula of the fingers: 2-2-3-3; atlas, the first vertebra relatively larger than the rest; vertebral column composed of eight presacral vertebrae; sacral vertebra relatively small, sacral diapophysis linear, not flattened or laterally expanded; ilia as long as the urostyle, converging at the ischium; femur long, more than $2 / 3^{\text {rd }}$ the length of the vertebral column; tibiofibula longer than femur; tarsus about half the length of tibia; metatarsals and phalanges of the foot long and slender; phalangeal formula: 2-2-3-4-3.

Natural history. A fairly common species found in evergreen forests; also occurs close to human habitation near puddles and streams. It can be heard calling at night time quite frequently during the rains. A pair in amplexus and freshly laid eggs was observed in late November in an evergreen forest patch on Great Nicobar (Fig. 7).

Distribution. Minervarya nicobariensis was recorded during this study from Camorta, Nancowry, Katchall and Great Nicobar. It was not recorded from Car Nicobar and Teressa Islands which were also surveyed for anurans during the present study (Fig. 8). It is endemic to the Nicobar Archipelago and does not occur in the Andaman Islands or elsewhere.

\section{Discussion}

Although the original description of Minervarya nicobariensis by Stoliczka (1870) was based on a specimen from "the neighbourhood of the Nancowry Harbor", on page 159 of the continuation of that article, under the accounts of Ptychozoon homalocephalum, Stoliczka (1870) states that he had obtained "one specimen at the Nancowry Harbor on Camorta", which reveals the fact that he refers to the Island of Camorta as Nancowry Harbour. Thus, the location from where the neotype has been designated now falls well within the original type locality mentioned by Stoliczka (1870). Following (or subsequent to) the loss of its single type specimen (Dubois 1984, Chanda et 


\section{Plate 57}

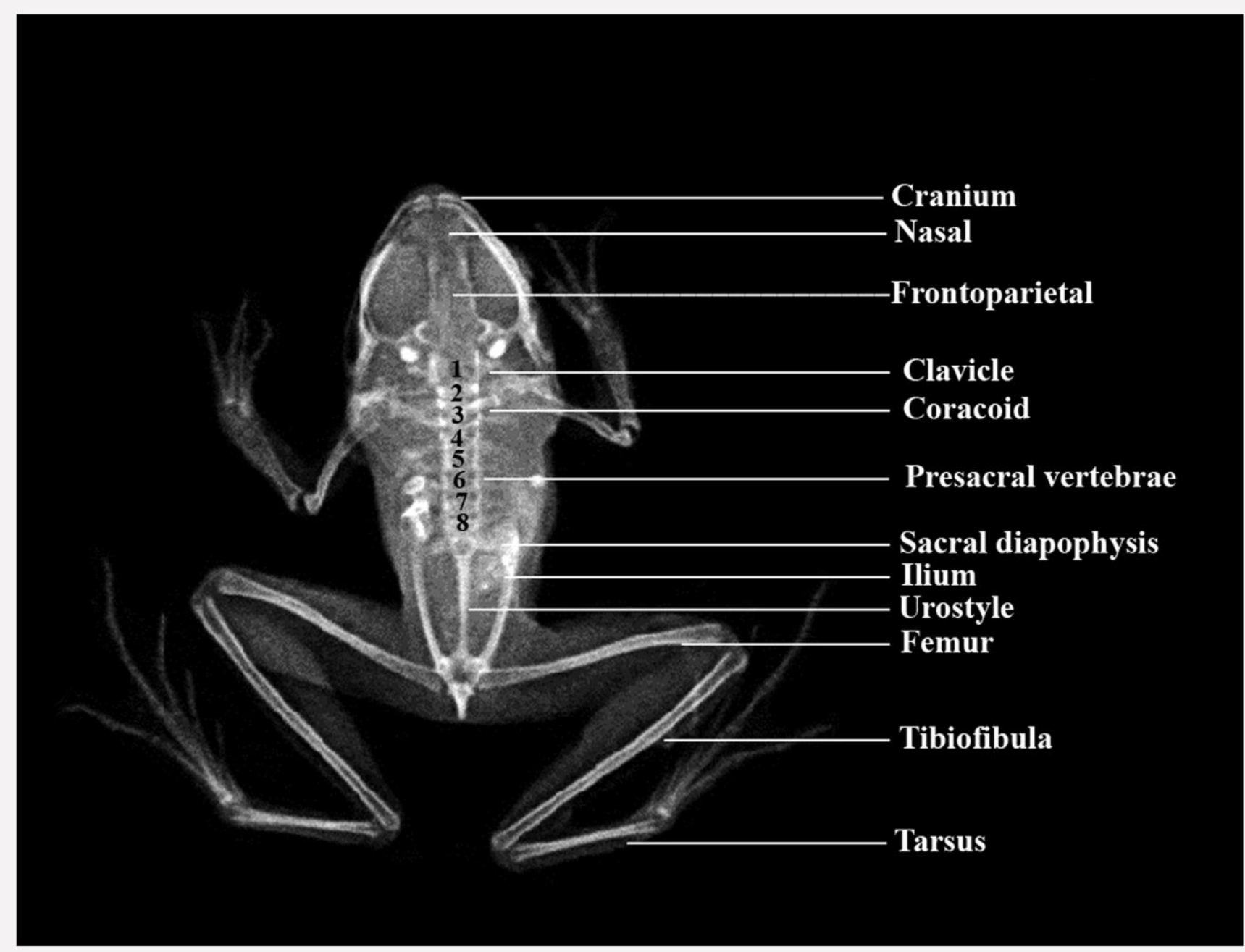

Figure 6. Radiograph showing the osteology of Minervarya nicobariensis specimen (DOSMB 05015) from Great Nicobar Island

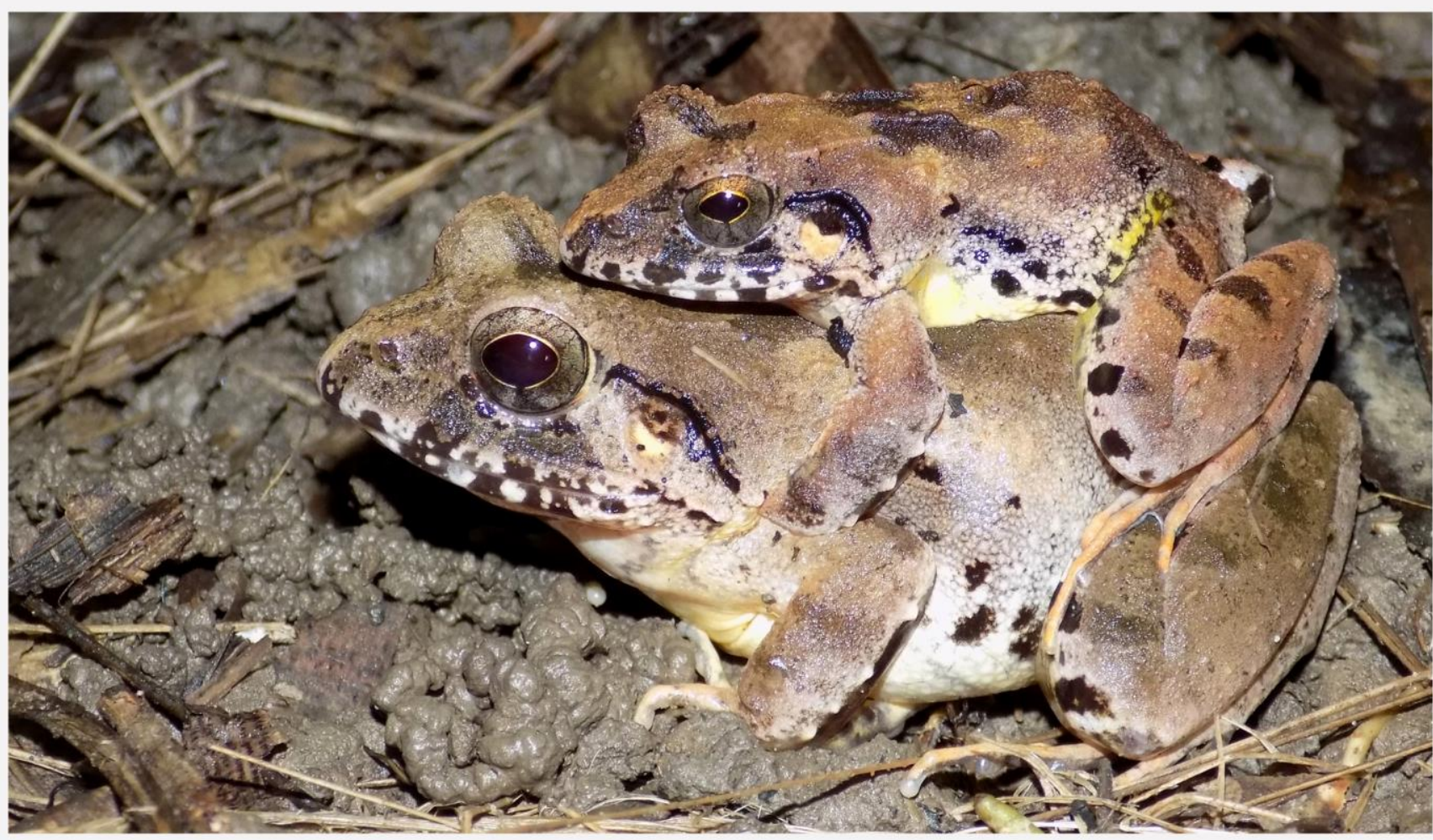

Figure 7. A pair of Minervarya nicobariensis in amplexus, observed in Great Nicobar Island 
al. 2001), the validity of the species was doubted and it was regarded as incertae sedis by Dubois (1987). Since then, there has been no taxonomic treatment of this taxon, except that of Dubois \& Ohler (2000) including this species under the genus Fejervarya. Taxonomic stability has been provided for this species through the designation of a neotype herein. Being unable to resolve the identities of some Dicroglossid frogs from the Andaman and Nicobar Islands, Harikrishnan \& Vasudevan (2018) remarked on their uncertain taxonomic status. However, an examination of some of their unidentified specimens (WII HS $44,46)$ revealed that they indeed represent the species Minervarya nicobariensis. This species is presently regarded as endangered (EN) by the IUCN. Its occurrence was recorded on at least four islands of the Nicobar archipelago during this study, totalling to about $1,400 \mathrm{~km}^{2}$ in area and is hence a highly range-restricted species facing threats that could result in its extinction.

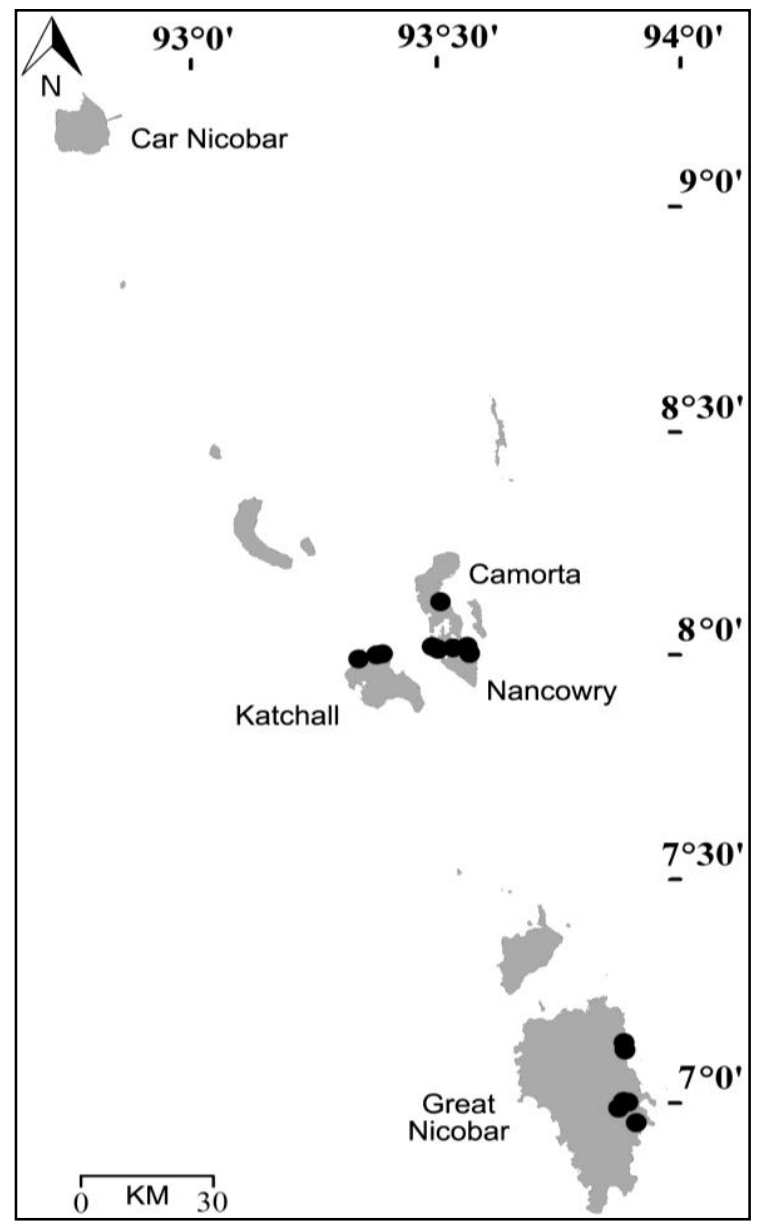

Figure 8. Distribution of Minervarya nicobariensis in the Nicobar Archipelago

\section{Acknowledgements}

We thank the Department of Environment \& Forests (Andaman \& Nicobar) for providing permission (Permit Nos: CWLW/WL/134/(J)/ Folder/417 and CWLW/WL/134(L)/60) and infrastructure for this study; and Department of Ecology \& Environmental Sciences and the Department of Ocean studies \& Marine Biology (Pondicherry University) for the lab space and support extended. C. Sivaperuman (Officer incharge, ZSI, Andaman \& Nicobar) is acknowledged for registering the neotype. Enrique La Marca (University of the Andes, Venezuela), Nikolay A. Poyarkov, Jr. (Lomonosov Moscow State University, Russia), and Philip Bowles (IUCN) are acknowledged for reviewing the manuscript. This study was partly supported by the Mohamed bin Zayed Species Conservation Fund (Grant No: 160514249).

\section{Literature cited}

Chanda, S.K., I. Das, and A. Dubois (2001). Catalogue of amphibian types in the collection of the Zoological Survey of India. Hamadryad, 25: 100-128.

Chandramouli, S.R. and A. Kalaimani (2014). Description of the larvae of Günther's toad Duttaphrynus hololius (Günther, 1876)(Anura: Bufonidae) with notes on development and oral ultra-structure. Alytes, 31: 3-12.

Dubois, A. (1984). Note preliminaire sur le groupe de Rana limnocharis Gravenhorst, 1829 (Amphibiens, Anoures). Alytes, 3: 143-159.

Dubois, A. (1987). Miscellanea taxinomica batrocholoica (I). Alytes, 5: 7-95.

Dubois, A. and A. Ohler (2000). Systematics of Fejervarya limnocharis (Gravenhorst, 1829) (Amphibia, Ranidae) and related species 1. Nomenclatural status and type specimens of the nominal species Rana limnocharis Gravenhorst, 1829. Alytes, 18: 15-50.

Harikrishnan, S. and K. Vasudevan (2018). Amphibians of the Andaman \& Nicobar Islands: distribution, natural history, and notes on taxonomy. Alytes, 36: 238-265.

Noble, G.K. (1931). The biology of the Amphibia. McGraw Hill Book Company, London: 577pp.

Sanchez, E., S.D. Biju, M.M. Islam, M. Hassan, A. Ohler et al. (2018). Phylogeny and classification of Fejervaryan frogs (Anura: Dicroglossidae). Salamandra, 54: 109-116.

Savage, J.M. and W.R. Heyer (1997). Digital webbing formulae for anurans: a refinement. Herpetological Review, 28: 131.

Sclater, W.L. (1892). A list of Batrachia of the Indian Museum. Taylor \& Francis, London: $575 \mathrm{pp}$.

Stoliczka, F. (1870). Observations on some Indian and Malayan amphibia and reptilia. Journal of the Asiatic Society of Bengal, 39: 134-228. 
- blank page -

TAPROBANICA VOL. 09: NO. 02 